\title{
MODERNIDADE DO DIREITO PROCESSUAL BRASILEIRO
}

\author{
Ada Pellegrini Grinover \\ Professora Livre-Docente de Processo Civil e Titular de Processo Penal \\ do Departamento de Direito Processual da Faculdade de Direito da USP
}

\begin{abstract}
Resumo:
Após um retrospecto sobre o direito processual brasileiro, o estudo detém-se na consolidação técnico-científica do processo, iniciada a partir de Liebman e marcando toda uma geração de processualistas. Passa depois a acentuar a fase crítica do direito processual, a partir dos estudos constitucionais e da teoria geral, examinando os grandes temas da atualidade (acesso à ordem jurídica justa, universalidade da tutela jurisdicional, efetividade e instrumentalidade do processo, participação). Finalmente, apontando para a reestruturação dos esquemas processuais clássicos, conclui pela modernidade do direito processual brasileiro que, na estrita fidelidade ao método técnico-científico, sabe conciliá-lo com as preocupações sócio-políticas.
\end{abstract}

\begin{abstract}
:
After a review of Brazilian Procedural Law, the study examines the technical-scientific consolidation of the Procedure that began with Liebman and that set its stamp on a whole generation of Procedure lawyers. It emphasizes next the critical phase of Procedural Law, from the constitutional studies and general theory, examining the great themes of our day (the acess to a just juridical order, the universality of the jurisdictional guardianship, the effectiveness and instrumentality of the procedure, participation). It points, finally, to a re-structuring of the classical procedural arrangements, its conclusion being that Brazilian Procedural Law is modern, it being able to conciliate its social and political preocupations with a strict fidelity to the technical-scientific method.
\end{abstract}

Sumário:

1. Antecedentes

2. A Escola Processual de São Paulo

3. A consolidação técnico-científica

4. Da fase conceitual à fase crítica do direito processual

4.1. Os estudos constitucionais do processo

4.2. A Teoria Geral do Processo 


\section{A posição sócio-política}

5.1. Acesso à ordem jurídica justa

5.2. A universalidade da jurisdição

5.3. Efetividade do processo

5.4. Instrumentalidade do processo

5.5. Participação e processo

5.6. As linhas de transformação no enfoque do processo

6. A revisitação dos institutos

6.1. O labor legislativo

6.2. Os mitos do processo tradicional

6.2.1. A reestruturação dos esquemas processuais civis: legitimação, coisa julgada e poderes processuais do juiz

6.2.2. A revisão dos princípios clássicos do processo penal: a verdade real e a indisponibilidade da ação penal pública

7. Conclusões

1.

A história do direito processual brasileiro começa em meados do século passado, com a figura ímpar de Paula Batista, Mestre da Faculdade de Olinda e Recife, ainda hoje altamente considerado pela profunda percepção de problemas fundamentais do processo civil (ação, demanda, execução), descortinando horizontes desconhecidos pela própria processualística européia da época. Para o processo penal, a mesma intuição se delineava nas obras de Pimenta Bueno. Seguir-se-iam, depois, João Monteiro, João Mendes Júnior e Estevam de Almeida, todos catedráticos da Faculdade de Direito de São Paulo, além de Galdino Siqueira, voltado ao processo penal. João Monteiro, que nos albores do século já vislumbrava a teoria da ação como direito abstrato; Estevam de Almeida que, a partir de 1911, deixava preleções de relevante valor jurídico, com referências à doutrina de Chiovenda e, mais tarde, de Carnelutti; e João Mendes Júnior que, na primeira República, tratou do processo civil e do processo penal à luz dos princípios comuns a ambos, numa verdadeira teoria geral do processo, ciência que só começaria a adquirir pujança, entre nós, há menos de vinte anos; que ainda surgia como precursor dos estudos constitucionais do processo, lançando as bases para a compreensão do devido 
processo legal; e que, ademais, edificava a "teoria ontológica do processo", colocando a disciplina nos parâmetros da concepção aristotélico-tomista das quatro causas e daí estabelecendo a nítida distinção entre processo e procedimento.

Assim, a partir da cátedra de processo civil, João Mendes supria as deficiências do processo penal que, com Galdino, não se afastava da escola procedimentalista francesa, já superada na Europa.

Mas esses foram os geniais precursores. Suas lições tardaram a espraiar-se e a doutrina brasileira de então ressentiu-se profundamente de grande desatualização metodológica, permanecendo ligada aos clássicos portugueses (Correia Telles, Pereira e Sousa, Lobão) e aos exegetas italianos do século passado (Mattirolo, Pescatore e, até certo ponto, Mortara) e não se alinhando ao movimento de renovação que a partir do século passado se instalara na Europa.

Só mais recentemente - por volta dos anos trinta -, surgiram processualistas mais afeitos ao novo método científico do direito processual e às suas modernas teorias.

E, no mesmo período, a promulgação do Código de Processo Civil unitário de 1939 produziu efeitos catalizadores, com repercussões profundas nos estudiosos brasileiros.

Para o processo civil, devem ser lembrados o grande Pontes de Miranda, alagoano radicado no Rio de Janeiro, que foi o primeiro, no Brasil, a conceituar o processo como relação jurídica; o paulista Gabriel de Rezende Filho, que estabeleceu a ligação entre o procedimentalismo dos Mestres anteriores e a renovação científica que ocorreu no Brasil a partir do Código de 1939; o carioca Machado Guimarães, construindo cientificamente as bases da processualística em muitos de seus institutos fundamentais; os mineiros Amílcar de Castro e Lopes da Costa, este com um tratado institucional que, embora escrito na vigência do estatuto anterior, ainda é um dos melhores que se escreveram em nosso país; no Recife, Torquato Castro; e mais um paulista, Moacyr Amaral Santos, com obra didática que grangeou grande prestígio, reeditada à luz do Código de 1973, e que ainda se mantém.

Também para o processo penal, os anos trinta marcaram uma nova fase e uma postura renovada. Perenes as lições do catedrático paulista Joaquim 
Canuto Mendes de Almeida, sobrinho de João Mendes Júnior, pela tentativa de se extrairem do velho processo criminal português os princípios fundamentais que estruturam o juízo penal e pela preocupação com a perspectiva constitucional do processo, deixando marcas indeléveis em muitos institutos processuais.

A renovação metodológica que se iniciara abria caminho para o franco ingresso do método científico na ciência processual brasileira. E a contribuição maior para a maturidade da processualística foi dada pela chegada de Enrico Tullio Liebman.

A vinda de Liebman, que se estabeleceu em São Paulo em 1940 para ficar até o final da guerra, não aportou apenas uma decisiva contribuição para a renovação do método do processo civil, mas significou também - e sobretudo a congregação, em torno de sua pessoa, de jovens estudiosos do direito processual, lançando as bases da Escola de São Paulo.

Liebman, portador da ciência européia do direito processual, mas também dominando por inteiro a obra dos autores luso-brasileiros mais antigos e o espírito da legislação herdada de Portugal; os talentosos processualistas brasileiros dos anos quarenta - reunidos em torno do Mestre para debaterem os grandes temas de sua ciência: surgiu desses elementos, em perfeita simbiose, o movimento científico do processo civil que desembocaria na construção de uma verdadeira escola, que Alcalá-Zamora chamaria, mais tarde, Escola Processual de São Paulo.

Constituíram essa Escola os discípulos de Liebman, que privaram de sua companhia nos encontros dos sábados à tarde: Alfredo Buzaid, José Frederico Marques, Luís Eulálio de Bueno Vidigal, Bruno Affonso de André, os quais souberam elevar a ciência processual a níveis científicos antes inimagináveis entre nós. E que continuariam, por muitas décadas, a oferecer um panorama processual de primeiríssima linha, em que se fixavam as grandes estruturas do sistema e amadureciam seus conceitos fundamentais.

Pertencem a essa fase metodológica não apenas os trabalhos científicos dos seus cultores, antes citados, mas também seu ponto culminante: o Código de Processo Civil de 1973, obra notável de Alfredo Buzaid, que inscreveria o sistema brasileiro entre os mais modernos e avançados do mundo. 
3.

Mas a Escola Processual de São Paulo transcendeu aos seus limites: não se exauriu com os primeiros discípulos de Liebman, nem no âmbito territorial de São Paulo; e a onda renovatória não se restringiria ao processo civil.

A consolidação técnico-científica do direito processual brasileiro já era irreversível.

Nos quatro cantos do país, publicam-se obras de fôlego. E os processualistas civis se multiplicam, identificados pela estrita fidelidade ao método técnico-científico e reunidos em torno de uma fundamental identidade de pensamento. São prova disto os trabalhos de Calmon de Passos, na Bahia; de Galeno Lacerda, Mendonça Lima, Ovídio Baptista da Silva e Furtado Fabrício, no Rio Grande do Sul; de Celso Barbi, José Olímpio de Castro Filho e Humberto Theodoro Jr., em Minas Gerais; de Ary Florêncio Guimarães e Moniz de Aragão, no Paraná; de Luiz Antônio de Andrade, Hamilton Moraes e Barros, José Carlos Barbosa Moreira e Sérgio Bermudes, no Rio; e, naturalmente, dos processualistas de São Paulo: Celso Neves, Lobo da Costa, Botelho de Mesquita, Cândido Dinamarco, Araújo Cintra, da Universidade de São Paulo; Mariz de Oliveira, Arruda Alvim e Donaldo Armelin, da Universidade Católica. E tantos outros, que seria impossível enumerar.

Pode-se dizer, sem temor de erro, que aquela que foi chamada Escola Processual de Sāo Paulo se transformou depois na Escola Brasileira, cuja unidade metodológica e cuja doutrina remontam seguramente ao espírito aglutinador de Liebman: deste à Escola Processual de São Paulo e daí para a moderna processualística brasileira, em uma continuidade de pensamento hoje reconhecida em toda parte e, mais que nunca, na Itália.

A onda renovatória fez-se sentir também no processo penal, seja pela obra do discípulo direto de Liebman, José Frederico Marques, que se dedicou tanto ao processo civil como ao processo penal, e cujas obras permanecem em todo seu vigor, constituindo consulta obrigatória; seja porque o amadurecimento do processo penal também se mostrava irreversível, como bem demonstram as obras de Hélio Tornaghi, no Rio, de Romeu Pires de Campos Barros, em Goiás, de Athos Moraes Velloso, no Paraná, de Xavier de Albuquerque, no Amazonas, de Tourinho Filho, em São Paulo, de Nilzardo 
Carneiro Leão, em Pernambuco. E também, nesse campo, o Código unitário, de 1941, provocou o reflorescimento dos estudos de processo penal.

Assim se completou, no Brasil, a fase conceitual do direito processual, marcada pelas grandes construções científicas.

4. Conquistadas as bases científicas do direito processual, consolidadas conceitualmente suas categorias e seus institutos, estabelecida a autonomia do processo, civil e penal, em relação ao direito material, os processualistas brasileiros puderam partir para outra fase metodológica, eminentemente crítica.

O processo, que até então era examinado numa visão puramente introspectiva e visto costumeiramente como mero instrumento técnico predisposto à realização do direito material, passou a ser examinado em suas conotações deontológicas e teleológicas, aferindo-se os seus resultados na vida prática, pela justiça que fosse capaz de fazer. E o processualista moderno, consciente dos níveis expressivos de desenvolvimento técnico-dogmático de sua ciência, deslocou seu ponto de vista, passando a ver o processo a partir de um ângulo externo, examinando-o em seus resultados junto aos consumidores da justiça.

Partiu, assim, a doutrina processual brasileira para a etapa instrumentalista do processo.

4.1. Para o desencadeamento desse novo método, crítico por excelência, foi de muita relevância o florescer do estudo das grandes matrizes constitucionais do processo. O direito processual constitucional, como método supra-legal de exame dos institutos do processo, significou sua análise a partir de dado externo, qual seja, o sistema constitucional, que nada mais é do que a resultante jurídica das forças político-sociais existentes na nação.

No Brasil, desde cedo, houve clima para os estudos constitucionais do processo. $\mathrm{E}$ isso porque a Constituição republicana de 1891 trasladou para o sistema jurídico muitos institutos do direito norte-americano, desde o princípio da unidade da jurisdição e da judicial review dos atos administrativos e legislativos, passando pelas garantias do due process of law e culminando com os instrumentos constitucionais de defesa das liberdades. 
Por isso já surgiam, nos albores do século, os trabalhos de Rui Barbosa, traçando com maestria as coordenadas processuais do controle da constitucionalidade das leis, tal como havia sido transplantado do sistema norteamericano para o brasileiro.

João Mendes Júnior despontaria depois, como verdadeiro precursor dos estudos constitucionais do processo, apontando as bases e fundamentos constitucionais das garantias individuais, quer no processo civil, quer no processo penal. Analisando, nessa ótica, o direito judiciário e o Poder Judiciário, traçou as bases do devido processo legal, enquanto processo necessário para assegurar os direitos subjetivos tutelados pelo direito material. E por surgir o processo como instrumento para a segurança constitucional dos direitos, deve ele ser plasmado de forma adequada, sendo uma espécie de processo natural e devendo o procedimento ser modelado segundo as formalidades definidas por lei nacional.

Mas, apesar desse precoce e promissor surgir, entre nós, do processo constitucional, a lição de seus primeiros cultores permaneceria sem eco durante longos anos. Até que a Escola Processual de São Paulo, inspirando-se na sensibilidade constitucional de Liebman e abeberando-se nos ensinamentos do grande Mestre uruguaio Couture, levasse os estudos processuais civis para a área do direito constitucional.

E vieram a lume, nos anos cincoenta, os estudos de Luiz Eulálio Bueno Vidigal sobre o mandado de segurança; de Alfredo Buzaid, sobre o mesmo instituto e ainda sobre a ação direta de inconstitucionalidade, esta objeto de obra em que submete o instituto a tratamento científico e sistemático, enquadrando um dos instrumentos do processo constitucional nas categorias da moderna processualística; de José Frederico Marques, cujos trabalhos em torno da jurisdição voluntária e sobre o princípio constitucional da proteção judiciária marcam o ponto inicial dos modernos estudos brasileiros sobre as garantias do devido processo legal.

Mais vinte anos deveriam passar, para que o processo constitucional tomasse renovado impulso e marcasse a produção científica dos anos setenta e oitenta. De nossa parte, escolhemos o tema das garantias constitucionais do direito de ação para o concurso de livre-docência em processo civil em 1973, e, com a edição do novo Código, analisamos suas disposições à luz 
da Constituição, em 1975. Seguiu-se nossa tese de cátedra para o direito processual penal (Liberdades públicas e processo penal: as interceptações telefônicas, 1976).

A partir daí, multiplicam-se os estudos de processo constitucional: em 1980, vem a lume a tese de doutorado de Kazuo Watanabe (Princípio da inafastabilidade do controle jurisdicional no sistema jurídico brasileiro), editada com outro ensaio sobre o mandado de segurança contra atos judiciais. Publicase, em 1985, sob nossa coordenação, volume de jurisprudência constitucional do Tribunal de Alçada Criminal de São Paulo. E em todas as obras processuais da década não faltam referências às garantias constitucionais.

Mais especificamente, em Minas Gerais, José Alfredo de Oliveira Baracho escreve monografia sobre o devido processo legal e Humberto Theodoro Jr. sobre a execução da sentença e o devido processo legal.

Outros fatores deram renovado impulso aos estudos constitucionais do processo: na Universidade de São Paulo, criada a disciplina de pós-graduação "Processo Constitucional", muitas dissertações e teses de mestrado-doutorado são apresentadas e defendidas; e, com os trabalhos preparatórios e a sucessiva promulgação da Constituição de 1988, rica em garantias processuais, os trabalhos multiplicam-se: Elival da Silva Ramos disserta sobre a ação popular constitucional como instrumento de participação política; Caio Mori sobre a ação direta de inconstitucionalidade; Luciano Marques Leite sobre o princípio audiatur et altera pars no processo penal. José Rogério Cruz e Tucci conquista a livre-docência com trabalho sobre a motivação da sentença no processso civil e Antônio Magalhães Gomes Filho defende tese de doutorado sobre a presunção de inocência e a prisão cautelar.

Nos anos noventa a produção continua: em nível acadêmico, Angélica de Maria Mello de Almeida disserta sobre o interrogatório do acusado como ampla defesa. No Rio, Luis Gustavo Grandinetti Carvalho escreve sobre o processo penal em face da Constituição e, no Ceará, Railda Saraiva, em estudo sobre a Constituição e o ordenamento jurídico penal, detém-se sobre as garantias do devido processo legal.

Numerosos os artigos de doutrina sobre o processo constitucional, nos anos oitenta e noventa: José Carlos Barbosa Moreira, em 1980, publica trabalho sobre a motivação das decisões judiciárias como garantia inerente ao 
Estado de Direito e, em 1984, sobre a garantia do contraditório na atividade de instrução; Calmón de Passos, em 1981, escreve sobre o devido processo legal e o duplo grau de jurisdição; numerosos os nossos ensaios da época, recolhidos nos volumes $O$ processo em sua unidade-II, de 1984, e Novas tendências do direito processual, de 1990. Em 1989, José Augusto Delgado publica artigo sobre os princípios essenciais da tutela do processo na Constituição de 1988.

E recentemente, em 1992, em colaboração com Antônio Scarance Fernandes e Antônio Magalhães Gomes Filho, publicamos livro sobre as nulidades no processo penal, todo voltado à dimensão constitucional das garantias.

4.2. Os estudos de processo constitucional criaram clima metodológico para o desenvolvimento de uma teoria geral do processo, pois é na Constituição, antes de mais nada, que se encontra a plataforma comum às diversas disciplinas processuais. Já tivéramos, no Brasil, um João Mendes Jr. e um José Frederico Marques, como precursores da visão dos grandes princípios comuns ao processo civil e ao penal. $O$ renovado interesse pelo direito processual constitucional, como método definidor dos grandes conceitos e estruturas do sistema, levou, na mesma linha, ao retorno do interesse pela teoria geral do processo, na qual se reúnem princípios gerais comuns aos vários ramos do direito processual, em uma visão crítica e unitária, capaz de introduzir ao conhecimento das distintas disciplinas processuais.

O impulso inicial foi dado pela implantação da disciplina, no âmbito curricular da Faculdade de Direito da Universidade de São Paulo, em 1973. Após um ano de ensino, os docentes encarregados da matéria - Antônio Carlos de Araújo Cintra, Cândido Rangel Dinamarco e Ada Pellegrini Grinover redigiram a primeira edição da Teoria geral do processo, publicada em 1974.

Decorridos quase vinte anos, introduziram-se alterações na sétima edição da obra, necessárias para adequá-la à nova ordem constitucional e às grandes transformações por que passaram a ciência processual e o próprio pensamento dos Autores nos últimos decênios. Mas o livro preserva, acentuando-o até, o método unitário de análise crítica dos fundamentos e dos institutos basilares do direito processual. 
Mas não é só. A disciplina foi oferecida também em nível de pósgraduação, a partir dos anos oitenta, na Faculdade de Direito da Universidade de São Paulo e diversas outras matérias, em nível de mestrado-doutorado, passaram a ser ali ministradas dentro da visão unitária dos grandes princípios processuais.

Concomitantemente, outras Faculdades de Direito do país introduziram em seus currículos a "Teoria Geral do Processo", ocasionando com isso novo interesse pela disciplina. Prova disto é o livro de Teoria geral do processo, editado em São Paulo em 1986, de autoria de José de Albuquerque Rocha e o de José Eduardo Carreira Alvim, publicado em 1989, no Rio.

Durante todo esse tempo, a matéria catalizou as atenções de docentes e alunos, tendo sido elaboradas e defendidas várias dissertações e teses, obedecendo ao enfoque metodológico de teoria geral, enfoque que hoje preside a muitas obras processuais.

Lembrem-se, apenas para exemplificar, em São Paulo, a dissertação de mestrado e a tese de doutorado de Antônio Scarance Fernandes, a primeira sobre prejudicialidade (1984) e a segunda sobre incidentes, questões e procedimentos incidentais (1989); e, no Rio de Janeiro, a tese de Paulo César Pinheiro Carneiro, sobre o Ministério Público na teoria geral do processo (1988).

Guardam a mesma postura metodológica muitos dos nossos artigos, reunidos em $O$ processo em sua unidade-I (1978), O processo em sua unidade-II (1984) e Novas tendências do direito processual (1990). E o recente Manual de processo penal, de Vicente Greco Filho (1991) é todo plasmado pela teoria geral do processo.

5. Estava preparado o terreno para mais um passo do processualista rumo à superação das colocações puramente técnico-jurídicas da fase conceitual do direito processual. Este passo foi dado, e os processualistas de última geração estão hoje envolvidos na crítica sócio-política do sistema, que transforma o processo, de instrumento meramente técnico em instrumento ético e político de atuação da Justiça substancial e garantia das liberdades. Processo esse que passa a ser visto na total aderência à realidade sócio-política a que se destina, para o integral cumprimento da sua vocação primordial, que é a efetiva atuação dos direitos materiais. Todo o sistema processual passa assim a ser considerado 
como instrumento indispensável para atingir os escopos políticos, sociais e jurídicos da jurisdição; e a técnica processual, como meio para a obtenção de cada um destes objetivos.

Examinem-se, nesse enfoque, os pontos basilares enfrentados pela doutrina processual brasileira, naquilo que oferece de mais original $e$ representativo.

5.1. Kazuo Watanabe escreve em 1988 estudo sobre "Acesso à Justiça na sociedade moderna" (in Participação e processo, São Paulo, Revista dos Tribunais, 1988, p. 128-135) em que demonstra que hoje a idéia de acesso à justiça não mais se limita ao mero acesso aos tribunais: não se trata apenas e somente de possibilitar o acesso à justiça enquanto instituição estatal, mas de viabilizar o acesso à ordem jurídica justa.

Dados elementares do direito à ordem jurídica justa são: $a$. o direito à informação; $b$. o direito à adequação entre a ordem jurídica e a realidade sócio-econômica do país; $c$. o direito ao acesso a uma justiça adequadamente organizada e formada por juízes inseridos na realidade social $\mathrm{e}$ comprometidos com o objetivo de realização da ordem jurídica justa; $d$. o direito à pré-ordenação dos instrumentos processuais capazes de promover a objetiva tutela dos direitos; $e$. o direito à remoção dos obstáculos que se anteponham ao acesso efetivo a uma justiça que tenha tais características.

5.2. Surge dessas idéias a tendência para a universalidade da tutela jurisdicional, a que se refere Cândido Dinamarco ( $A$ instrumentalidade do processo, São Paulo, Revista dos Tribunais, 1987, p. 391-405), pela qual se oferece a mais ampla admissão de pessoas e causas ao processo.

Para isso, é preciso eliminar, antes de mais nada, os óbices econômicos que impeçam ou desestimulem as pessoas de litigar ou dificultem o oferecimento de defesa adequada. A promessa constitucional de assistência jurídica integral e gratuita há de ser cumprida, seja no juízo cível como no criminal, de modo que ninguém fique privado de ser convenientemente ouvido pelo juiz, por falta de recursos.

Mas é preciso também remover os obstáculos jurídicos representados pela dificuldade de litigar para a defesa dos novos direitos que surgem na sociedade de massa (interesses supra-individuais), abrindo as portas 
para o ingresso de novas causas, pelos esquemas reformulados da legitimação para agir.

E é preciso facilitar o acesso à justiça (e à ordem jurídica justa) não só aos carentes econômicos, como também aos juridicamente necessitados, dentre os quais avultam na sociedade moderna os carentes organizacionais, mais vulneráveis em face das relações sócio-econômicas (os titulares de pequenos conflitos, os consumidores, os partícipes de contratos de adesão, os usuários de serviços públicos, os pequenos investidores no mercado mobiliário, os segurados da Previdência Social, etc.): cf. nosso trabalho sobre $O$ acesso à Justiça no ano 2000, publicado pela OAB-DF por ocasião da XIV Conferência Nacional da OAB, Vitória, setembro de 1992.

Inserem-se finalmente na idéia de universalidade da proteção jurisdicional as técnicas de revitalização das vias alternativas que, embora nem sempre jurisdicionais, se colocam num amplo quadro de política judiciária, como meios de solucionar conflitos fora do processo e sem necessidade deste: a conciliação e a arbitragem, poderosos instrumentos de desafogo da litigiosidade contida, na feliz expressão cunhada por Kazuo Watanabe, e cujo principal fundamento é a pacificação social (cf. Cândido Dinamarco, ob. cit., p. 404; Ada Pellegrini Grinover, "A conciliação extrajudicial no quadro participativo", in Novas tendências do direito processual, Rio, Forense Universitária, 1990, p. 216233).

5.3. A efetividade do processo é outro ponto fundamental nas preocupações do processualista contemporâneo.

A partir de um ensaio de José Carlos Barbosa Moreira, publicado pela primeira vez em 1982, firmaram-se os pontos essenciais desse conceito: $a$. o processo deve dispor de instrumentos de tutela adequados a todos os direitos (e às outras posições jurídicas de vantagem) contemplados no ordenamento, resultem eles de expressa previsão normativa, ou inferíveis do sistema; $b$. esses instrumentos devem ser praticamente utilizáveis, sejam quais forem os supostos titulares dos direitos (e das outras posições jurídicas de vantagem), inclusive quando indeterminado ou indeterminável o círculo dos sujeitos; $c$. é preciso assegurar condições propícias à exata e completa reconstituição dos fatos relevantes, a fim de que o convencimento do julgador corresponda, tanto quanto 
possível, à realidade; $d$. em toda a extensão da possibilidade prática, o resultado do processo há de ser tal que assegure à parte vitoriosa o pleno gozo da utilidade específica a que faz jús segundo o ordenamento; $e$. esses resultados hão de ser atingidos com o mínimo dispêndio de tempo e energia (Barbosa Moreira, "Notas sobre o problema da 'efetividade' do processo", in Temas de direito processual, São Paulo, Saraiva, 1984, p. 27-42).

O tema da efetividade do processo foi retomado por Cândido Dinamarco, na tese de cátedra publicada em 1987 (Dinamarco, $A$ instrumentalidade...ob. cit., p. 451-453), em que o autor assim resume os aspectos fundamentais da problemática da efetividade: $a$. acesso à Justiça; $b$. modo de ser do processo; $c$. critérios de julgamento (ou "justiça nas decisões") e $d$. a efetivação dos direitos (ou "utilidade das decisões").

5.4.

A problemática da instrumentalidade do processo, profundamente ligada à da efetividade - sobre as quais já havia discorrido Barbosa Moreira ("Tendências contemporâneas do direito processual civil", in Temas...ob. cit., p. 2-6), constituiu o tema central da tese de Cândido Dinamarco de 1987, acima referida, cujos destaques fundamentais e conclusões mais amplas são os seguintes:

a. falar em instrumentalidade exige que se esclareçam os fins a serem atingidos pelo instrumento, considerados os escopos jurídico, social e político da jurisdição (ou do processo como sistema): escopo jurídico, de atuação dos direitos materiais; escopo político, de participação; escopo social, de pacificação com justiça; $b$. é preciso extrair do caráter instrumental do processo os desdobramentos teóricos e práticos, colocando o processo em seu devido lugar, evitando os males do exagerado "processualismo" (como aspecto negativo da instrumentalidade) e cuidando ao mesmo tempo de predispor o processo e seu modo de uso de modo tal que os objetivos sejam convenientemente conciliados e realizados (aspecto positivo da instrumentalidade). Nesse enfoque, sem transigir quanto à autonomia do direito processual, relativiza-se o binômio "substância-processo"; c. sem renegar as conquistas teóricas do período de apogeu técnico-científico do direito processual, devem elas ser canalizadas para um pensamento crítico $\mathrm{e}$ inconformista, de modo que, sem prejuízo da 
introspecção do sistema, este seja também encarado de ângulos externos (seus escopos) (ob. cit., p. 435-438).

5.5. Liga-se à questão dos escopos políticos da jurisdição (e do processo como sistema) a relativa ao momento participativo.

A participação, no interior do processo, cumpre-se por intermédio do princípio do contraditório, pelo que toma relevância o conceito de processo como procedimento em contraditório (sem exclusão da idéia de relação processual), realçado por Dinamarco, na tese citada (p. 442 e 444-5) e, mais recentemente, por Aroldo Plínio Gonçalves (Técnica processual e teoria do processo, Rio de Janeiro, Aide, 1992, p. 102-132). E toma relevância o papel do juiz no processo, como verdadeiro partícipe da relação processual (Barbosa Moreira, sobre a "participação" do juiz no processo civil, in Participação $e$ processo, coord. de Ada Pellegrini Grinover, Cândido Dinamarco e Kazuo Watanabe, São Paulo, Revista dos Tribunais, 1988, p. 380-394).

Mas, além disso, o princípio participativo sugeriu um rumo de investigações dirigidas, total ou parcialmente, fora do âmbito estrito da atividade realizada em juízo. Trata-se agora de examinar a relação entre participação no sentido mais amplo de participação popular - e processo, aferindo os meios de interferência que os indivíduos ou os grupos sociais assumem diante do processo.

E se notou que, embora o núcleo da participação encontre seus momentos fundamentais na intervenção, na tomada das.decisões e no seu controle, desdobra-se ela numa imensa variedade de formas, que vão desde a informação e a tomada de consciência, a orientação jurídica e $o$ encaminhamento, passando pelas consultas e reivindicações e chegando à realização dos serviços (ver, de nossa autoria, "A conciliação extrajudicial...' in Novas tendências...ob. cit., p. 222-223).

Por isso mesmo, pode-se desenhar um amplo quadro atinente ao princípio participativo, ligado à jurisdição e ao processo. Tem-se, de um lado, a participação na administração da Justiça e, do outro, a participação mediante a Justiça.

A participação na administração da Justiça, que responde às exigências de legitimação democrática do exercício da jurisdição, pode fazer-se por meio da intervenção popular direta ou indireta. 
A intervenção popular direta compreende a presença de leigos na fase instrutória e decisória e os procedimentos de escolha dos juízes. A indireta configura o controle da função jurisdicional pelos destinatários, ora mediante as relações Justiça-informação (com a problemática inerente à publicidade dos atos processuais, passando pelo controle dos meios de comunicação até o sigilo, com publicidade restrita às partes e a seus procuradores); ora pelas técnicas de aferição da legalidade e justiça das decisões (e a correlata obrigatoriedade de motivação); ora pelas técnicas de responsabilização do juiz; ora pelos controles sobre a atuação e inércia dos órgãos da acusação no processo penal.

Já a participação mediante a justiça utiliza o próprio instrumento "processo" para permitir o acesso das pessoas e das causas à Justiça e à ordem jurídica justa, ligando-se à questão da universalidade da tutela jurisdicional. $O$ próprio processo é então utilizado como veículo de participação democrática, e por ele se possibilita a intervenção popular na urdidura do tecido social. A começar pela assistência jurídica que compreende a informação, a tomada de consciência e o encaminhamento aos canais processuais ou alternativos adequados -, passando pela assistência judiciária e culminando com a abertura dos esquemas da legitimação para a causa, que permite o acesso de vastas parcelas da população por intermédio dos portadores, em juízo, de suas pretensões, em se tratando de interesses transindividuais, cuja veiculação em juízo em processos coletivos assume relevante dimensão social e política (cf. Ada Pellegrini Grinover, "A conciliação extrajudicial...", in Novas tendências...ob. cit., p. 222-225).

A importância da participação no processo e pelo processo foi salientada por seminário internacional, realizado em São Paulo em meados de 1988, com a presença de processualistas estrangeiros e brasileiros, do qual resultou a publicação do livro Participação e processo, contendo ensaios de numerosos juristas brasileiros: Calmón de Passos, Ovídio Baptista da Silva, Cândido Dinamarco, Kazuo Watanabe, Elival da Silva Ramos, Antônio Magalhães Gomes Filho, Rodolfo de Camargo Mancuso, Humberto Peña de Moraes, Walter Piva Rodrigues, Oscar Xavier de Freitas, Octávio Bueno Magano, Ada Pellegrini Grinover, Carlos Alberto Carmona, Waldemar Mariz de Oliveira Júnior, Athos Gusmão Carneiro, Antônio Scarance Fernandes, José 
Carlos Barbosa Moreira, Vicente Paulo Tubelis e José Antonio de Paula Santos Neto (pela ordem dos trabalhos publicados).

5.6. As linhas de transformação do enfoque do processo, à luz dos pontos centrais acima relatados, consubstanciam-se nas tendências atuais do direito processual, que Barbosa Moreira, em outro ensaio antológico, publicado em 1984 , dividiu em três vertentes: $a$. do abstrato ao concreto ; $b$. do individual ao social; e $c$. do nacional ao internacional (Barbosa Moreira, "Tendências contemporâneas do direito processual civil", in Temas...ob. cit., p. 1-13).

A tendência que desloca o interesse dos processualistas da linha abstrata para a concreta nada mais representa do que o empenho pela efetividade e instrumentalidade do processo, já examinadas.

Os esforços pela transformação do processo individualista, cunhado para acudir a conflitos de interesses individuais, num processo social, adequado à sociedade contemporânea, confluem num movimento em que, como aponta Barbosa Moreira (Tendências...ob. cit., p. 6-11), duas linhas-força podem ser identificadas: de um lado, o processo desperta para a necessidade de assegurar a tutela jurisdicional a conflitos de interesses que, por sua dimensão metaindividual, mal se acomodam no quadro dos esquemas processuais clássicos; de outro, busca imprimir ao próprio tratamento dos conflitos interindividuais feição mais consentânea com certas exigências básicas do Estado social de direito, facilitando o acesso à justiça, independentemente de desníveis culturais, sociais e econômicos, de modo a tornar operativo o princípio no plano substancial. As duas vertentes, como se viu, espelham a preocupação central do processualista contemporâneo em seus esforços rumo à universalidade da tutela jurisdicional.

Finalmente, a passagem de um processo nacional para o transnacional afeiçoa-se ao fenômeno generalizado em que se assiste à progressiva diminuição de importância das fronteiras nacionais diante de fatores sociais, culturais, políticos e econômicos. E assim, no plano processual, intensificam-se os esforços para assegurar a cooperação das justiças dos vários países. Tratados e convenções que interessam à atividade jurisdicional se multiplicam. Desenvolve-se o juízo arbitral no terreno do comércio internacional, inspirando reformas legislativas. Os ordenamentos tornam-se mais permeáveis ao reconhecimento de decisões de justiças estrangeiras, perdendo 
prestígio a solução consistente em subordinar sua eficácia à aferição prévia da justiça da decisão, mediante a revisão da causa. Evolui o tratamento processual do direito estrangeiro que seja relevante para a decisão do litígio, segundo as regras de direito internacional privado, de modo que as questões de direito estrangeiro, ao menos para efeitos práticos, se equiparam a meras questões de fato (Barbosa Moreira, ob. cit., p. 11-13).

E mais: empenham-se os processualistas ibero-americanos - e dentre eles muitos brasileiros na tarefa de cunhar Códigos-modelo para o processo civil e o processo penal, elaborando propostas de integração imediatamente operantes e que possam servir de norte aos diversos países na elaboração de seus códigos nacionais. Os Códigos-modelo, redigidos com a colaboração de juristas brasileiros por incumbência do Instituto IberoAmericano de Direito Processual, respondem à imperiosa exigência de estimular um profundo movimento de reforma nos países da comunidade hispano-lusoamericana e oferecem um modelo institucional, rico de mecanismos adequados para responder às exigências do processo moderno (Cf. Ada Pellegrini Grinover, "Lineamentos gerais do novo processo penal na América Latina: Argentina, Brasil e Código-modelo para Ibero-América", Revista de Processo, São Paulo, n. 58, p. 120-134, 1990).

Ao mesmo tempo, os processualistas brasileiros participam de congressos e encontros internacionais, neles assumindo posição de relevo; são convidados para conferências no exterior e são citados por autores estrangeiros; freqüentam com seus trabalhos as páginas de revistas alienígenas e integram as diretorias de Associações e Institutos internacionais de processo. Pode-se mesmo dizer, com Barbosa Moreira, que "o Brasil tem voz nos conselhos mundiais, é entidade que pesa. Se dependesse só do direito processual, seria bem diferente, sem dúvida, a imagem externa do País...' (Reflexões sobre direito e sobre processo: duas geraçōes de processualistas brasileiros, separata, Rio de Janeiro, 1992, p. 28).

6.

Dentro da linha de transformação do processo abstrato para o concreto, buscando a efetividade e instrumentalidade do processo, empenhado no esforço rumo à universalização da jurisdição e ao acesso à ordem jurídica justa e levando em conta as transformações sociais, o processualista brasileiro 
contemporâneo inicia o trabalho de revisitação dos institutos processuais clássicos, para adaptá-los à nova realidade.

O fato é que a sensibilidade sócio-política do processualista não o levou, nem deve levá-lo, a menosprezar o rigor científico de sua matéria. E a novidade da orientação dos estudos processuais brasileiros, que os distingue de outros de igual tendência sociológica, é a estrita fidelidade ao método técnicocientífico. Conciliando e fundindo o pensamento e o método técnico-científico com as preocupações sócio-políticas, o processualista brasileiro da atualidade dedica-se - tanto no processo civil como no penal - aos problemas atuais do processo, na plena observância de seus cânones científicos mais rigorosos, empregando escrupulosamente a técnica processual para atingir os diversos escopos da jurisdição.

E isso porque, como foi notado por um dos mais sensíveis processualistas brasileiros contemporâneos, menosprezar a dimensão técnica do direito é formidável equívoco, pois qualquer ciência demanda e se serve de instrumentos técnicos. Se é certo que o tecnicismo exacerbado esteriliza o direito, é igualmente certo que o direito sem técnica é reduzido a diletantismo, quando não a charlatanismo (José Carlos Barbosa Moreira, Reflexões...ob. cit., p. 26-27). E, nas palavras de outro processualista da atualidade, há que conciliar o aspecto instrumental do processo, o qual é uma realidade ética porque permeado dos influxos dos valores substanciais eleitos pela nação, com a necessidade de operacionalizar meios para a consecução do que se deseja (Cândido Dinamarco, A instrumentalidade...ob. cit., p. 320).

6.1. Por isso mesmo, na última década o processualista empenhou-se em trabalhos legislativos, permeados de sua nova visão.

Assim, colaborou ele ativamente na preparação de vários diplomas legais, extremamente avançados quanto à concepção filosófica e trazendo a marca de uma impecável técnica processual: a Lei de Pequenas Causas (Lei n. 7.244, de 7 de novembro de 1884); a Lei da Ação Civil Pública (Lei n. 7.347, de 24 de julho de 1985); o Código de Defesa do Consumidor (Lei n. 8.078, de 11 de setembro de 1990).

O processualista brasileiro de ủitima geração também participou ativamente da elaboração da Constituição de 1988, que contém inúmeros 
dispositivos processuais-constitucionais, igualmente progressistas: entre as garantias do devido processo legal, ganharam estatura constitucional a regra da obrigatoriedade de motivação das decisões judiciárias e da publicidade dos atos processuais; a garantia do juiz natural em seu aspecto de juiz competente; a regra da inadmissibilidade das provas obtidas por meios ilícitos. Para o processo penal, foram elevados a nível constitucional a presunção de não-culpabilidade e o direito ao silêncio; os controles sobre a prisão, inclusive pela previsão de indenizações; o monopólio da ação penal pública nas mãos do MP, com o controle da ação penal privada subsidiária da pública. Além disso, novos instrumentos de tutela das liberdades foram cunhados, como o mandado de segurança coletivo e o mandado de injunção. Abriram-se os esquemas da legitimação às ações coletivas de associações, partidos políticos, sindicatos, do MP, de comunidades indígenas, assim como foi ampliada a legitimação à ação direta de inconstitucionalidade. Institucionalizaram-se, em nível constitucional, a conciliação extrajudicial, assim como Juizados especiais para causas cíveis de menor complexidade e infrações penais de menor potencial ofensivo, prevendose para ambos a conciliação, o procedimento oral e sumaríssimo e o julgamento de recursos por turmas formadas por juízes de primeiro grau.

E o processualista continua empenhado em colaborar na elaboração de importantes projetos legislativos: as pequenas causas penais, a ampliação da lei de pequenas causas cíveis, as interceptações telefônicas, o tratamento dos crimes de colarinho branco, a nova lei ambiental, as modificações parciais dos códigos processuais civil e penal com vistas à simplificação e celeridade do processo, tudo espelha o engajamento do processualista contemporâneo, que alia a rigorosa técnica à sensibilidade sócio-política e contribui decisivamente para o aperfeiçoamento das instituições.

6.2. Nesse trabalho de reestruturação do processo, necessário para adequá-lo aos escopos sociais e políticos da jurisdição, muitos dos esquemas processuais clássicos tiveram que ser revisitados, com o objetivo de adaptá-los à realidade sócio-política da sociedade contemporânea.

Alguns mitos da processualística tradicional foram redimensionados, passando a obedecer a novos modelos, adequados às instâncias de nosso tempo: recordem-se, para o processo civil, a legitimação para 
a causa, a coisa julgada e os poderes do juiz no processo; e, para o processo penal, o princípio da verdade real e o da indisponibilidade da açāo penal pública, abrindo-se a rigidez do sistema para a autonomia da vontade.

6.2.1. a. A legitimação para a causa foi tradicionalmente comprimida, pela processualística clássica, nos limites da coincidência entre a titularidade do direito material e a titularidade da ação. É exatamente esta a postura do Código brasileiro de 1973, em seu art. $6^{\circ}$.

Percebe-se facilmente que só por intermédio de arrojadas construções doutrinárias, avançadas por processualistas que percebiam a necessidade de adaptar os esquemas clássicos às instâncias de nosso tempo (como José Carlos Barbosa Moreira e Kazuo Watanabe) e por uma jurisprudência pioneira e corajosa, seria possível enquadrar nos estreitos limites do art. $6^{\circ}$ do CPC a legitimação de entes públicos e associações às ações coletivas em defesa de interesses transindividuais: estes não se titularizam, por definição, nas mãos de um detentor individualizado, e pela doutrina clássica os entes ou associações que levassem a juízo os interesses coletivos ou difusos não agiriam por direito próprio, mas sim na qualidade de substitutos processuais, não sendo essa legitimação extraordinária prevista em lei.

O primeiro passo foi dado pela Lei da Ação Civil Pública, de 1985, que legitimou expressamente às ações coletivas o MP, outros entes públicos e as associações que, pré-constituídas há pelo menos um ano, tivessem entre seus fins institucionais a defesa dos bens e direitos protegidos pela lei. A Constituição de 1988, como visto, ampliou o arsenal das ações coletivas, mantendo fundamentalmente os princípios inseridos na LACP, com o acréscimo da legitimação ativa do partido político e a supressão do MP para o mandado de segurança coletivo. E o mesmo esquema foi preservado pelo Código de Defesa do Consumidor, que acrescentou a legitimação de entes públicos, ainda que despersonalizados, destinados especificamente à tutela dos bens em questão. Paralelamente, o CDC determinou a aplicabilidade de suas normas processuais à defesa dos direitos e interesses difusos, coletivos $e$ individuais (evidentemente, quando tratados coletivamente, por sua origem comum) da LACP, pelo que o exercício da ação civil pública foi estendido à defesa de direitos ou interesses individuais homogêneos, coletivamente tratados, com a mesma legitimação. 
Estava, assim, garantido o acesso à justiça a amplos segmentos da população, pela via das ações coletivas, por intermédio dos portadores, em juízo, dos interesses ou direitos difusos, coletivos e individuais homogêneos. $E$ assegurada, de um lado, a participação popular pelo processo e, de outro, a consecução dos fins jurídicos, sociais e políticos da jurisdição.

b. Quanto à coisa julgada, a doutrina processual já estava consolidada no sentido de limitar subjetivamente às partes a imutabilidade da sentença e de seus efeitos, condenando, ainda, de modo mais ou menos generalizado, o regime da coisa julgada secundum eventum litis, ou seja, de acordo com o resultado do processo.

É certo que o nosso sistema jurídico já havia se aberto à coisa julgada erga omnes, nas hipóteses de ação popular constitucional (Lei n. 4.717/65); e que a mesma lei havia avançado em direção a uma particular espécie de coisa julgada secundum eventum litis, quando se oferecia ao juiz a possibilidade de pronunciar o non liquet, nos casos de improcedência por insuficiência de provas.

Não foi difícil, então, acolher a mesma solução na LACP. Mas o CDC foi além: não só agasalhou os princípios da Lei da Ação Popular e da LACP, para os processos coletivos em defesa de interesses difusos e coletivos; mas ainda, ao regular os processos em defesa de direitos ou interesses individuais homogêneos, coletivamente tratados, adotou igualmente a coisa julgada erga omnes, mas agora secundum eventum litis, no significado mais completo: ou seja, a sentença de improcedência, nas demandas coletivas em defesa de direitos ou interesses individuais homogêneos, impede outras ações coletivas de objeto e fundamento iguais, mas não obsta às ações individuais que, a título pessoal, cada titular do direito queira ajuizar.

A solução do direito brasileiro, diversa da adotada nas class actions do sistema da common law, apresentava-se como a mais aderente à realidade sócio-econômica brasileira e às nossas peculiaridades sobre a legitimação dos substitutos processuais; não incorria nas dificuldades que o critério norteamericano do opt out ainda comporta; e não feria o princípio constitucional da igualdade (nem mesmo como igualdade de chances), porque de qualquer modo a sentença condenatória, no processo coletivo em defesa de interesses ou direitos individuais homogêneos, se limita a reconhecer a existência do dano geral e o 
dever de indenizar, cabendo depois a cada interessado, em processos de liquidação necessariamente individualizados, provar o seu dano pessoal e o nexo etiológico, além de quantificar a indenização, tudo em cognição exauriente e contraditório pleno.

Observe-se, finalmente, ainda com relação à coisa julgada (agora vista em seus limites objetivos, tradicionalmente contidos no dispositivo da sentença), que só aparentemente o CDC estendeu aos motivos a coisa julgada, quando determinou que os efeitos da coisa julgada positiva, nas ações em defesa de interesses difusos e coletivos, beneficiassem os titulares de direitos pessoais, para o fim de procederem à liquidação e execução da sentença. Na verdade, trata-se aqui de efeitos secundários da sentença coletiva, ou da ampliação legal do objeto da demanda coletiva, cuja sentença também deixa certo o dever de indenizar aos particulares. Exatamente como já ocorria, no nosso ordenamento, com relação aos efeitos civis da sentença penal condenatória.

c. O Código de Processo Civil, de 1973, já havia preparado o caminho para investir o juiz de uma soma maior de poderes na condução do processo. Antes disso, a legislação do trabalho havia forjado soluções que limitavam o princípio dispositivo. E o legislador de 1985 e 1990 ampliou a trilha aberta por seus antecessores.

A LACP previu que, no cumprimento das obrigações de fazer ou não fazer, o juiz não ficaria necessariamente adstrito à imposição do preceito cominatório, consistente na clássica multa diária, podendo determinar, quando a entendesse insuficiente ou incompatível, o cumprimento da prestação da atividade devida ou a cessação da atividade nociva, sob pena de execução específica. De outro lado, se a multa diária fosse suficiente e compatível com a obrigação, poderia o juiz aplicá-la, independentemente de pedido do autor. Possibilitou, ainda, a lei de 1985 , que o juiz conferisse aos recursos efeito suspensivo, para evitar dano irreparável à parte.

Por sua vez, o CDC manteve o precedente da LACP quanto à execução específica; e ainda, avançando mais, deixou claro que o juiz poderia emitir qualquer espécie de provimento jurisdicional, legítimo e adequado, para propiciar a efetiva tutela dos direitos e interesses protegidos pelo Código. Quanto aos processos coletivos de responsabilidade civil, estruturou a sentença condenatória de modo que o juiz nela averigüasse a respeito dos prejuízos 
causados (e não dos prejuízos sofridos), tanto assim que a condenação é genérica e a indenização, se não houver habilitantes em número compatível com a gravidade do dano, poderá reverter ao Fundo criado pela LACP.

6.2.2. a. Para o processo penal, o princípio tradicional da verdade real, pelo qual ao juiz penal e às partes seria permitida toda e qualquer atividade instrutória capaz de levar à descoberta da verdade, foi comprimido dentro de lindes intransponíveis, destinados a resguardar a dignidade humana e a intimidade. Princípios éticos proclamados na Constituição e regras jurídicas, que levam em consideração valores inerentes aos direitos da personalidade, conduziram à revisão do princípio da verdade real, visto outrora como instrumento essencial para a realização do poder punitivo do Estado, e agora redimensionado como verdade subtraída da influência das partes, mas sempre constitucional e processualmente válida.

A inviolabilidade da intimidade, da vida privada, da honra e da imagem das pessoas e de suas emanações (a inviolabilidade do domicílio e do sigilo da correspondência e das comunicações); a garantia contra a tortura e tratamentos degradantes; o direito à identificação dos responsáveis pela prisão ou pelo interrogatório; a assistência da família e do advogado, no momento da prisão, e o direito ao silêncio; a inadmissibilidade das provas obtidas por meios ilícitos e a presunção de não culpabilidade; as garantias da motivação e os limites da prisão processual, tudo foi estruturado pela Constituição de modo a realçar os princípios éticos na obtenção da verdade real, dando novo enfoque ao princípio tradicional.

b. Por outro lado, ao prever Juizados Especiais para infrações penais de menor potencial ofensivo, a própria Constituição abrandou o princípio da indisponibilidade da ação penal pública, permitindo a transação em matéria penal e abrindo caminho para a mitigação do princípio da obrigatoriedade, por intermédio da denominada discricionariedade regulada por lei, que toma corpo e avança nos sistemas processuais penais da atualidade. E o projeto de lei das pequenas causas penais, bem como o anteprojeto de lei ambiental, propóem outras técnicas em homenagem ao princípio da autonomia da vontade, como a suspensão condicional do processo e o aumento de hipóteses de ação penal condicionada à representação. 
7. Concluindo, pode-se dizer que o caminho do direito processual brasileiro moderno percorreu três fases distintas:

a. a primeira, de índole técnico-científica que, numa visão interna do sistema, consolidou conceitualmente as categorias e os institutos do processo, estabelecendo rigorosamente os fundamentos do direito processual;

b. a segunda, eminentemente crítica, que, passando pelos estudos constitucionais e pela edificação de uma teoria geral do processo, examina-o a partir de um ângulo externo, considerando-o em seus aspectos deontológicos e teleológicos, aferindo seus resultados junto aos consumidores de justiça;

c. a terceira, em que o processualista torna a dirigir suas preocupações à técnica processual, utilizando-a para revisitar os institutos processuais, a fim de adequá-los à nova realidade, no esforço de edificar um sistema apto a atingir os escopos, não só jurídicos, mas também sociais e políticos da jurisdição.

Mas uma coisa é certa: não se deve censurar à geração anterior de processualistas o enfoque eminentemente técnico-científico com que conduziram seus estudos e pesquisas. A fase anterior foi necessária para que o direito processual se elevasse a patamares antes desconhecidos entre nós e foi capaz de dar à ciência do processo seus fundamentos teóricos, suas estruturas básicas, seus institutos primordiais.

Como bem disse Barbosa Moreira, "sem o valioso acervo que recebeu, não poderia certamente a minha geração de processualistas sequer tentar as empresas que tentou, com o êxito de que acredita ter algumas razóes para orgulhar-se. Desse passado imediato, ela nada quis, nem quer, rejeitar. Seu lema não foi, nem é, o da renegação, mas o da complementação" (Reflexões...ob. cit., p. 27).

Complementação que se fez, utilizando a rigorosa técnica que nos foi legada, no sentido de transformar o processo num instrumento a serviço de valores mais elevados: o acesso à Justiça e à ordem jurídica justa; a universalidade da tutela jurisdicional; a efetividade e instrumentalidade do processo, posto a serviço dos escopos jurídicos, sociais e políticos da jurisdição; a participação no processo e pelo processo: tudo dentro das linhas evolutivas que levaram o sistema processual do abstrato ao concreto, do individual para o social, do nacional ao transnacional. 
Eis aí a modernidade do direito processual brasileiro, cuja novidade consiste na estrita fidelidade ao método técnico-científico, mas conciliando-o e fundindo-o com as preocupações sócio-políticas.

\section{BIBLIOGRAFIA}

CINTRA, Antonio Carlos de Araújo; GRINOVER, Ada Pellegrini; DINAMARCO, Cândido Rangel. Teoria geral do processo. São Paulo : Revista dos Tribunais, 1974.

DINAMARCO, Cândido Rangel. A instrumentalidade do processo. São Paulo : Revista dos Tribunais, 1987.

GONÇALVES, Aroldo Plinio. Técnica processual e teoria do processo. Rio de Janeiro : Aide, 1992.

GRECO FILHO. Vicente. Manual de processo penal. São Paulo : Saraiva, 1991. GRINOVER, Ada Pellegrini. O acesso à Justiça no ano 2000. In: XIV Conferência Nacional da OAB, Vitória, 1992.

----. Liberdades públicas e processo penal: as interceptaçōes telefônicas. São Paulo : Revista dos Tribunais, 1976.

----. Lineamentos gerais do novo processo penal na América Latina: Argentina, Brasil e Código modelo para Ibero-América. Revista de Processo, São Paulo, n. 58, p. 120-34, 1990.

----- Novas tendências do direito processual. Rio de Janeiro : Forense Universitária, 1990.

MOREIRA, José Carlos Barbosa. Notas sobre o problema da "efetividade" do processo. In: Moreira, José Carlos Barbosa Temas de direito processual. São Paulo : Saraiva, 1984.

----.. Reflexões sobre direito e sobre processo: duas gerações de processualistas brasileiros. Rio de Janeiro, 1992.

----. Sobre a participação do juiz no processo civil. In: GRINOVER, Ada Pellegrini; DINAMARCO, Cândido Rangel \& WATANABE, Kazuo, coord. Participação e processo. São Paulo : Revista dos Tribunais, 1988.

----. Tendências contemporâneas do direito processual civil. In: Moreira, José Carlos Barbosa. Temas de direito processual. São Paulo : Saraiva, 1984. 
WATANABE, Kazuo. Acesso à Justiça na sociedade moderna. In: GRINOVER, Ada Pellegrini; DINAMARCo, Cândido Rangel \& WATANABE, Kazuo, coord. Participação e processo. São Paulo : Revista dos Tribunais, 1988.

-----. Princípio da inafastabilidade do controle jurisdicional no sistema jurídico brasileiro. São Paulo, K. Watanabe, 1979. 